\title{
ENTRE O PLENÁRIO E O ESTÚDIO: UM OLHAR JURÍDICO SOBRE O USO DA MÍDIA POR PARLAMENTARES DA ASSEMBLEIA DE MINAS GERAIS
}

\author{
BETWEEN THE PLENARY AND THE STUDIO: A LEGAL LOOK ON THE USE OF MEDIA BY \\ PARLIAMENTARIANS IN THE STATE ASSEMBLY OF MINAS GERAIS
}

André Rubião

Doutor em Ciência Política (Universidade Paris 8), mestre em Filosofia do Direito (Universidade Paris 8), é professor na Faculdade de Direito Milton Campos e na UNIFENAS. E-mail: andrerubiao@hotmail.com

\section{Sílvia Pires Volpini}

Bacharel em Comunicação Social (Jornalismo) pela Pontifícia Universidade Católica de Minas Gerais e em Letras pela Universidade Federal de Minas Gerais. Graduanda em Direito pela Faculdade de Direito Milton Campos. E-mail: silvolpini@gmail.com

Recebido em: 26.08.2015

Aprovado em: 10.02 .2016

DOI:10.5585/rdb.v12i5.293

\section{Resumo}

Este artigo discute o uso da mídia por parlamentares, sob uma perspectiva jurídica, com base num estudo de caso envolvendo deputados da Assembleia Legislativa de Minas Gerais. Parte-se da hipótese de que algumas práticas adotadas por eles entram em conflito com princípios e regras do ordenamento jurídico brasileiro. Os argumentos da pesquisa podem ser divididos em quatro eixos principais: i) o anúncio de comerciais por deputados é um ato dissonante à moralidade administrativa; ii) os desequilíbrios gerados pela superexposição midiática vão contra a isonomia; iii) a ausência aos compromissos oficiais em decorrência das atividades na mídia fere o regimento interno parlamentar; e iv) o acúmulo de cargos é passível de questionamento em face das incompatibilidades elencadas nas Constituições Federal e Estadual. O artigo conclui ser necessário criar dispositivos normativos que impeçam expressamente parte dessas práticas e que reforcem os mecanismos capazes de analisar alguns casos concretos.

Palavras-Chave: Prática parlamentar. Mídia. Princípio da moralidade. Ética profissional. Poder Legislativo. 


\begin{abstract}
This article discusses the use of media by parliamentarians under a legal perspective, based on a case study involving members of the Legislative Assembly of Minas Gerais. It begins with the hypothesis that some practices adopted by members conflict with rules and principles of Brazilian law. The research arguments can be divided into four main areas: i) the commercial ads done by deputies are dissonant to administrative morality; ii) the imbalances generated by media overexposure goes against equality; iii) the parliamentarians absences due to appointments as a result of their activities in the media hurts parliamentary regulations; and iv) the accumulation of positions allows for questionability given the incompatibilities listed in the Federal and State Constitutions. The article concludes by saying that it is necessary to create regulatory provisions that seek to tackle some of these practices and to strengthen the mechanisms to examine individual cases.
\end{abstract}

Keywords: Parliamentary practice. Media. Moral principle. Professional ethics. Legislative Power.

Sumário: Introdução; 1 Os parlamentares mineiros radialistas; 2 Políticos comunicadores e a moralidade administrativa; 3 A exposição midiática e o princípio da igualdade; 4 Os deputados radialistas e a frequência na ALMG; 5 As incompatibilidades constitucionais e a função em empresas radiodifusoras: uma leitura possível?; Considerações finais. Referências.

\title{
Introdução
}

O capital político é uma forma de capital simbólico, crédito firmado na crença e no reconhecimento ou, mais precisamente, nas inúmeras operações de crédito pelas quais os agentes conferem a uma pessoa - ou a um objeto - os próprios poderes que eles lhes reconhecem. (BOURDIEU, 2012, p. 128)

Ao lançar o conceito de capital político, nos anos 1970, Bourdieu (2012) postulava que a conquistada de espaço no cenário político estaria fortemente atrelada a uma relação de reconhecimento entre um grupo social e alguns indivíduos. O autor identificava na superexposição midiática um poderoso "atalho" para a criação de uma condição eleitoral, baseada na identificação e na transferência de expectativas. Assim, a geração de capital político (um ganho de credibilidade perante os eleitores) parecia depender, cada vez mais, da visibilidade dos candidatos nos meios de comunicação. 
A partir desse marco teórico, que chamava a atenção para o risco de assimetrias e efeitos perversos que o poder simbólico da mídia poderia gerar, uma série de pesquisas envolvendo as relações entre os meios de comunicação e o campo político começaram a despontar no ambiente acadêmico. No Brasil, podemos destacar os trabalhos de Silva (2000), Nunes (2000) e Costa (2007), que analisaram o desempenho de candidatos radialistas, em São Paulo, Fortaleza e Londrina, respectivamente. De forma geral, esses estudos apontam para a mesma direção: quando o comunicador transfere a credibilidade que possui no rádio e na TV para sua figura como candidato, o público dos programas acaba personificando nele a solução de seus problemas, revestindo-o de um potencial de representação.

Por outro lado, nenhum desses trabalhos nos permite concluir que o fato de esses comunicadores não terem construído preliminarmente uma carreira política e de terem grande visibilidade na mídia faz com que eles sejam políticos despreparados ou sem legitimidade no processo eleitoral. A livre participação dos cidadãos na democracia, já nos advertiam os Modernos, é um dos direitos que constitui a essência do Estado constitucional. Mas isso não significa que essa relação entre política e atores inseridos nos meios de comunicação não possa ser questionada sob vários aspectos.

Este artigo busca trazer uma abordagem jurídica para essa temática. Se a literatura que trata das relações entre mídia e poder parece estar solidificada nos âmbitos da Sociologia, da Comunicação e da Ciência Política ${ }^{1}$, raros são os estudos no campo do Direito. Pretendemos apresentar os resultados de um estudo de caso envolvendo deputados comunicadores da Assembleia Legislativa de Minas Gerais (ALMG), com vistas a discutir certas práticas adotadas por eles, à luz do ordenamento jurídico brasileiro e do direito comparado.

É interessante notar que, mesmo após serem eleitos, esses parlamentares continuam exercendo suas funções na mídia, muitas vezes com programas diários em rádios locais. Trata-se, no mínimo, de uma situação delicada. Prova disso é que alguns países, como a África do Sul, proíbem o acúmulo de cargos por parte dos parlamentares, e outros, como os Estados Unidos, trazem uma série de limitações, inclusive de ordem remunerativa, para que eles possam exercer outra profissão. No Brasil, é preciso admitir, não há qualquer dispositivo legal que proíba expressamente essa conduta, no entanto, alguns contextos que envolvem a participação desses

\footnotetext{
${ }^{1}$ O panorama detalhado sobre a trajetória dos estudos sobre mídia e política no Brasil, bem como suas tendências, ver Rubim e Azevedo (1998).
} 
deputados comunicadores se apresentam de forma tão questionável, que é preciso lançar um olhar mais perspicaz sobre sua realidade jurídica.

Afinal, seria condizente com a conduta dos homens públicos fazer propaganda de produtos comerciais durante programas de rádio? E deixar de comparecer às seções em Plenário para se dedicar aos compromissos profissionais? Seria justo eles se aproveitarem desse espaço, de ordem privada, na mídia, para divulgar seus trabalhos de deputados? E condicionar o sorteio de produtos, oferecidos por patrocinadores, à curtida de suas páginas nas redes sociais, onde também constam seus trabalhos parlamentares?

Não há dúvidas de que essas práticas trazem inquietações para um espírito republicano. Muitas delas, como veremos mais adiante, são expressamente proibidas por legislações de outros países, mas acabam persistindo no Brasil, sob a velha batuta de que aquilo que não é proibido é permitido.

Nosso principal objetivo é questionar essa realidade. Não é de hoje o raciocínio, doutrinário e jurisprudencial, que permite superar o estrito legalismo, por meio de um novo paradigma hermenêutico, ancorado na valorização da força normativa dos princípios constitucionais e na análise argumentativa do caso concreto (HESSE, 1991; DWORKIN, 1997; ALEXY, 1997; BARROSO, 2004). Tendo esse quadro analítico em mente, nossas perguntas aparecem de forma natural: i) Será que as condutas dos deputados comunicadores passariam pelo crivo do princípio da moralidade na administração? ii) O que falar, com base no princípio da isonomia, do desequilíbrio eleitoral proporcionado pela superexposição midiática desses políticos com relação aos outros candidatos? iii) Muito além disso, sendo as rádios concessões públicas, não estariam esses deputados, com base no Art. 54 da Constituição Federal (correspondente ao Art. 57 da Constituição do Estado de Minas Gerais), infringindo o decoro parlamentar?

No seu diagnóstico da Modernidade, Max Weber teve o mérito de mostrar a consolidação da política como profissão (viver não somente "para" esse ofício, mas também “desse” ofício), algo que não existia na realidade cultural dos Antigos (WEBER, 2003). Mas se um retorno ao civismo espontâneo e gratuito dos gregos nos parece algo impossível hoje em dia, não podemos caminhar para o ponto em que a profissão política misture-se com outras formas de poder simbólico, sendo ameaçada por tensões permanentes ou ficando em segundo plano. Nesse sentido, ao apresentar o estudo de caso envolvendo os parlamentares mineiros (2), falar da moralidade na administração pública (3), questionar a falta de igualdade criada pela exposição 
midiática (4), analisar a assiduidade dos parlamentares às reuniões ordinárias da Assembleia (5) e discutir a constitucionalidade do acúmulo de cargos (6), este artigo pretende contribuir para o debate, pertinente na atual conjuntura, em torno dos critérios para se exercer um cargo eletivo.

\section{Os parlamentares mineiros radialistas}

A participação de profissionais da mídia na política nacional não é um fenômeno raro nem recente. Segundo Costa (2007), radialistas têm sido eleitos para variados cargos no Legislativo e no Executivo desde a década de 1950, à exceção da Presidência da República, que nunca foi ocupada por um comunicador de origem. O único a chegar mais próximo foi Anthony Garotinho - cujo apelido veio do rádio -, que ficou em $3^{\circ}$ lugar na disputa pelo Palácio do Planalto em 2002. Outro exemplo emblemático é o do apresentador de TV Celso Russomanno, que está no quinto mandato como deputado federal e já foi candidato à Prefeitura de São Paulo.

No legislativo mineiro, foco desta pesquisa, oito parlamentares da ALMG atuam ou já atuaram na linha de frente em veículos de comunicação. Os deputados estaduais Alencar da Silveira Jr. (PDT) e Felipe Attiê (PP) tiveram participação marcante no rádio antes de ingressarem na vida política. Entretanto, atualmente, ambos renunciaram às atividades na mídia. Leandro Genaro (PSB), Gilberto Abramo (PRB) e Vanderlei Miranda (PMDB) também possuem espaços em emissoras de rádio e TV, mas no segmento evangélico. ${ }^{2}$ Por fím, os deputados eleitos Douglas Melo (PSC), locutor da Rádio Musirama, de Sete Lagoas; João Vítor Xavier (PSDB) e Mário Henrique Caixa ${ }^{3}$ (PC do B), ambos da Rádio Itatiaia, serão especialmente considerados nesta análise, uma vez que ocupam espaços em rádios populares do estado concomitantemente ao exercício na Assembleia Legislativa.

Entre eles, observamos um ponto semelhante destacado por outras pesquisas que cuidam do fenômeno de políticos comunicadores. Trata-se da emergência dos políticos outsiders,

\footnotetext{
${ }^{2}$ Por se tratar de deputados com forte influência dentro de suas igrejas, acreditamos que a exposição midiática não pode ser analisada singularmente. Isso porque o discurso gospel tem suas peculiaridades e um público-alvo definido, com repercussões diferentes sobre o campo político. Por isso, decidimos por não incluir os três deputados em nossa investigação.

${ }^{3} \mathrm{O}$ deputado Mário Henrique Caixa tomou posse regularmente na Assembleia Legislativa de Minas Gerais em $1^{\circ}$ de fevereiro de 2015, mas em 16 de abril do mesmo ano foi nomeado pelo governador Fernando Pimentel ao cargo de Secretário de Estado de Turismo. Para fins desta análise, tomaremos como base o período em que ele ocupou a cadeira na atual legislatura da ALMG.
} 
conceito que designa o homem público que não tem histórico de formação ou militância partidária antes de estrear nos cargos eletivos (COSTA, 2007).

A biografia desses três comunicadores eleitos deputados estaduais no pleito de 2014 parece apontar para essa noção. De acordo com as informações divulgadas em seus sites e perfis oficiais na internet, João Vitor Xavier, Mario Henrique Caixa e Douglas Melo não tiveram atuação política antes de se tornarem jornalistas e locutores. Diferentemente, alcançaram seus primeiros mandatos quando já haviam conquistado espaço e visibilidade nas rádios.

João Vitor Xavier, por exemplo, atua na Rádio Itatiaia desde 2000 e ocupou seu primeiro cargo público na Câmara dos Vereadores, em 2008. Mário Henrique, profissional do rádio há 19 anos, concorreu ao pleito de 2010 na ALMG, mas não foi eleito. Em 2013, com a renúncia de Carlin Moura, tomou posse na condição de suplente, vindo a se reeleger na legislatura posterior. Por fim, Douglas Melo se elegeu o vereador mais jovem da história de Sete Lagoas, em 2012, quando já participava do programa “O Povo no Rádio”, destaque de audiência da Rádio Musirama.

\section{Políticos comunicadores e a moralidade administrativa}

A moralidade administrativa integra o rol de princípios positivados pela Constituição Federal de 1988, o que sobreleva sua importância no ordenamento jurídico brasileiro. Mesmo antes disso, a moralidade já havia sido incorporada à legislação pátria, muitas vezes de maneira indireta ou diluída em outras noções, como a probidade administrativa, a proteção e a guarda da coisa pública e até mesmo a possibilidade de responsabilização dos agentes públicos por abuso e desvio de poder. Nesse sentido, pondera a Ministra Cármen Lúcia Rocha:

A despeito de ser a corrupção um dos males gravíssimos do Brasil, o princípio da moralidade administrativa, se não vinha expresso no sistema constitucional que precedeu à ordem promulgada em 5 de outubro de 1988, também não era estranho ao Poder Público brasileiro. No discurso legal, desde os primeiros momentos de sua existência, são adotadas as mais variadas práticas no Estado brasileiro sob o argumento de busca da moralidade pública. (ROCHA, 1994, p. 216). 
A repercussão da moral no direito público se deu especialmente no Direito Administrativo, com o trabalho pioneiro de Maurice Hauriou, no início do século XX. ${ }^{4} \mathrm{~A}$ concepção inicial elaborada pelo jurista francês, e reverberada ainda hoje pelos estudiosos do tema, esboça a moralidade administrativa como "conjunto de regras de conduta tiradas da disciplina interior da Administração" (BRANDÃO, 1951 apud ROCHA, 1994, p. 189). Distinto da moral comum, o princípio tinha especial fundamento na legalidade administrativa e atrelava-se fortemente à questão do desvio de finalidade. $\mathrm{O}$ tratamento da moralidade no sentido da boa administração também foi aventado pela primeira vez na tese de Hauriou, cujos trabalhos tiveram importância incontestável para a introdução definitiva do princípio na doutrina e, por conseguinte, nos textos normativos.

No direito contemporâneo, a moralidade administrativa certamente ganhou contornos mais amplos. Além de erguer-se autonomamente às balizes da legalidade, passou a apoiar-se no domínio da garantia dos valores expressos na ideia do bem e da honestidade, a eivar de vício quaisquer comportamentos de agentes públicos que ofendam a moral, os princípios de justiça e equidade, o dever geral da boa administração, o interesse público, a boa-fé etc.

Essa perspectiva ampliada do princípio serviu como ensejo, por exemplo, à vedação do nepotismo nos três poderes em Ação Declaratória de Constitucionalidade 12, votada pelo Supremo Tribunal Federal em 2008. Em seu voto, o Ministro Celso de Mello destacou a moralidade administrativa como "valor constitucional revestido de caráter ético-jurídico e cláusula legitimadora e validadora de todos os atos estatais” (BRASIL, 2008, p. 29). A decisão representa, portanto, a absoluta aplicabilidade do princípio a situações que contrariem a essência democrática e a ordem constitucional, apesar de não apresentarem expresso impedimento legal. ${ }^{5}$

Na Constituição Federal de 1988, o princípio da moralidade administrativa está manifestadamente assentado em dois momentos distintos, nos art. $5^{\circ}$, LXXIII, e art. 37, caput. ${ }^{6}$

\footnotetext{
${ }^{4}$ A moralidade administrativa ganhou os holofotes da literatura jurídica brasileira, sobretudo, após sua inserção como princípio no texto constitucional de 1988. O percurso seguido por este trabalho na compreensão do tema dialoga, em especial, com os estudos de Rocha (1994), Moreira Neto (1992), Tácito (1999) e Di Pietro (2012).

${ }^{5}$ Em análise sobre a decisão do STF que reconheceu a ilegitimidade da nomeação de parentes para cargos públicos em comissão, ressalta Luís Roberto Barroso (2013): "A tese central sustentada na ADC contrariava essa visão tradicional, sendo acolhida no cerne no neoconstitucionalismo: os princípios constitucionais devem ser direta e imediatamente aplicáveis, ao menos no seu núcleo mínimo de sentido independentemente da atuação do legislador, e eventualmente, mesmo contra ela. Assim sendo, a proibição do nepotismo decorreria diretamente da Constituição, com base em princípios como os da moralidade e da impessoalidade" (p. 371).

6 “Art. 5', LXXIII - qualquer cidadão é parte legítima para propor ação popular que vise a anular ato lesivo ao patrimônio público ou de entidade de que o Estado participe, à moralidade administrativa, ao meio ambiente e ao
} 
Nota-se, inclusive, que o primeiro dispositivo estatui instrumento para coibir a imoralidade, atribuindo a qualquer cidadão legitimidade para propor ação popular que busque anular ato que ofenda o princípio. Obviamente há também referências infraconstitucionais, dentre as quais cabe destacar a Lei $n^{\circ}$ 9.784/99, que regula o processo administrativo no âmbito da Administração Pública Federal e cujo art. $2^{\circ}$ determina obediência ao princípio da moralidade (caput) e atuação segundo padrões éticos de probidade, decoro e boa-fé (parágrafo único, inciso IV).

A exigência de moralidade administrativa entre os governantes é reflexo de um Estado marcadamente presente na organização econômica e no domínio social. A configuração intervencionista agigantou o Estado e trouxe a reboque a necessidade de agentes incorruptíveis, responsáveis e verdadeiramente engajados aos objetivos de representar os interesses da sociedade (ROCHA, 1994). No quadro atual, a classe política brasileira experimenta há algumas décadas uma crise de descrédito e desmoralização, inflamada por sucessivos escândalos de corrupção e descaso com a coisa pública, o que acentua ainda mais as reivindicações por condutas consonantes ao senso comum de honestidade e justiça.

Tomando por base o espectro da moralidade administrativa delineado até aqui, partimos a conjecturar sobre algumas situações práticas envolvendo deputados radialistas, em busca de discutir uma possível incompatibilidade com o status do homem público idealizado para aqueles que alcançaram cargos nas esferas de poder mediante o voto dos eleitores brasileiros.

Propomos, neste ponto, um debate sobre a pertinência da realização de anúncios de empresas privadas e instituições públicas por políticos que atuam em emissoras de rádio, seja como apresentadores, comentaristas, repórteres ou locutores. Entre os parlamentares observados na pesquisa, verificou-se ser uma conduta frequente dos comunicadores emprestar voz e espaço a propagandas de companhias dos mais variados ramos ao longo da programação.

A título de exemplificação, durante a partida entre Independiente Santa Fe, da Colômbia, e Atlético Mineiro, pela Copa Libertadores ${ }^{7}$, o narrador esportivo da Rádio Itatiaia e então deputado estadual Mário Henrique Caixa ofereceu publicidade a nove empresas privadas, entre elas, uma rede varejista de eletrodomésticos, uma cooperativa médica, uma construtora, um

patrimônio histórico e cultural, ficando o autor, salvo comprovada má-fé, isento de custas judiciais e do ônus da sucumbência.” (BRASIL, 1988).

“Art. 37 - A administração pública direta e indireta de qualquer dos Poderes da União, dos Estados, do Distrito Federal e dos Municípios obedecerá aos princípios de legalidade, impessoalidade, moralidade, publicidade e eficiência e, também, ao seguinte: [...].” (BRASIL, 1988).

${ }^{7}$ A partida foi realizada numa quarta-feira, dia 18 de março de 2015, na cidade de Bogotá, na Colômbia. 
banco e uma empresa de telefonia móvel, além de destacar comerciais da Prefeitura de Belo Horizonte.

No ar diariamente sob o comando do programa "Bastidores", do mesmo canal, o jornalista e deputado estadual João Vítor Xavier alterna sua participação entre o noticiário esportivo e diferentes anúncios publicitários, cujas marcas vão desde uma empresa de salgados a uma prestadora de serviços de assistência veicular.

O ponto crucial levantado nesses casos é que, ao dar voz a tais propagandas, ambos os parlamentares estariam exercendo a atividade de profissionais de mídia, ocupação paralela ao posto na Assembleia Legislativa. Há de se destacar que a prática de promover os anunciantes da rádio não é restrita somente a eles, diferentemente, é rotina comum à quase totalidade dos repórteres, comentaristas e locutores da estação. A questão a ser colocada, entretanto, é que, uma vez investidos legitimamente em um cargo público, os políticos radialistas não poderiam, por conveniência própria, despir-se de tal investidura para tomar lugar em outra profissão.

A função pública transferida aos deputados por meio do voto não deve ser manipulada como um adorno ou uma indumentária, da qual ele se desveste arbitrariamente para se encarregar de outro ofício. Somente a lei pode determinar as hipóteses em que um deputado será afastado de suas atribuições. À exceção de raras eventualidades, o compromisso dos parlamentares deve ser sempre com a vontade popular e a soberania nacional, aliados aos parâmetros éticos de boa-fé, decoro e respeito aos preceitos constitucionais. ${ }^{8}$ Quando um deputado prestigia uma empresa privada durante a programação do rádio, fazendo-se valer de sua credibilidade e audiência com os ouvintes, ele se desvirtua da responsabilidade maior que tem com o interesse público e com sua função fiscalizadora.

A contribuição trazida pelo direito comparado mostra a preocupação de alguns países com a moralização da vida política no que tange à participação de parlamentares em anúncios publicitários. No Estatuto dos Deputados de Portugal, por exemplo, está entre o rol de

\footnotetext{
${ }^{8}$ No Regimento Interno da Assembleia Legislativa de Minas Gerais, há menções diluídas de alguns dos elementos fundantes do princípio da moralidade administrativa, vide a Resolução $\mathrm{n}^{\circ}$ 5.207/02, Art. $2^{\circ}$ do Capítulo I, Disposições Preliminares, dentro das quais destacamos:

"Art. $2^{\circ}$ - Consideram-se incompatíveis com a ética e o decoro parlamentar:

I - o abuso de prerrogativa constitucional ou legal;

II - a inobservância das vedações do art. 57 da Constituição do Estado, diretamente ou por intermédio de terceiros;

III - a percepção de vantagem indevida;

IV - a prática de irregularidade no desempenho do mandato ou de encargo dele decorrente, compreendidos:

a) o ato que atente contra a dignidade da investidura, do Poder Legislativo e das instituições democráticas;

b) a promoção de interesse contrário aos fins do poder público; [...].” (MINAS GERAIS, 2015).
} 
impedimentos expressos "figurar ou de qualquer forma participar em actos de publicidade comercial." $"$ Da mesma forma, o estatuto francês diz que, "para evitar qualquer prejuízo à dignidade da função parlamentar, um deputado ou um senador não pode usar da sua qualidade para fins publicitários.",10

O questionamento das condutas de deputados comunicadores pela via da moralidade administrativa pode ainda ser corroborado por outros argumentos, como o fato de a superexposição midiática poder ter desdobramentos decisivos sobre a campanha e a aprovação desses parlamentares. Essa premissa será tema debatido na seção seguinte.

\section{A exposição midiática e o princípio da igualdade}

No contexto das democracias representativas contemporâneas, é notória e inconteste a noção de que a disputa pelos cargos públicos eletivos deva se dar em um ambiente de estrita igualdade de oportunidades. Essa ideia pode ser observada tanto pela via da proibição do tratamento discriminatório, como pela via da exigência de intervenção estatal para garantir o equilíbrio igualitário (MENDES, 2010). Dessa forma, como corolário do princípio da isonomia construído na Constituição Federal, a Lei Eleitoral brasileira (Lei 9.504 de 1997) estipula uma série de regras atinentes à propaganda e à exposição de candidatos nos meios de radiodifusão, restringindo-se, porém, apenas ao período que antecede as eleições.

Quando os candidatos são apresentadores ou comentaristas em programas de rádio e TV, a Lei estipula que, a partir da escolha nas convenções partidárias, previstas para ocorrer entre 12 e 30 de junho do ano das eleições, é vedado às emissoras transmitir a atração com a participação do postulante a cargo político (Art. $45, \S 1^{\circ}$ ). Após o período eleitoral e mesmo durante os mandatos, parlamentares comunicadores podem regressar aos seus postos na imprensa.

A questão da igualdade durante a corrida eleitoral é abordada genericamente pelo Art. 45, IV. Pelo texto da norma, fica proibido às emissoras de rádio e TV "dar tratamento privilegiado a candidato, partido ou coligação”. Conforme observam Odyr Porto e Roberto Porto

\footnotetext{
9 Os impedimentos constam do Art. $21^{\circ}, \mathrm{n}^{\circ}$ 6, " $f$ ", do referido Estatuto português. Disponível em: <http://www.parlamento.pt/Legislacao/Documents/Legislacao_Anotada/EstatutoDeputados_Simples.pdf $>$. Acesso em: 21 jun. 2015.

${ }^{10}$ Os impedimentos constam na ficha síntese $\mathrm{n}^{\circ}$ 16, cap. III. Disponível em: <http://www2.assembleenationale.fr/decouvrir-l-assemblee/role-et-pouvoirs-de-l-assemblee-nationale/le-depute/le-statut-du-depute >. Acesso em: 21 jun. 2015.
} 
(1998), uma decisão do Tribunal Regional Eleitoral de São Paulo, logo no mesmo ano de promulgação da Lei Eleitoral, reforçou o texto sob a seguinte justificativa: "Ainda que não tenha havido pedido de voto, o fato é que, em ano eleitoral, o destaque de um candidato em detrimento dos demais, em emissora de rádio, fere o princípio constitucional da igualdade, regra básica para assegurar um pleito equilibrado.” (SÃO PAULO, 1997 apud PORTO; PORTO, 1998, p. 89).

Ainda no mesmo Art. 45, determina-se que redes de rádio e TV ficam impedidas de veicular o nome de qualquer programa que remeta a um candidato a partir de $1^{\circ}$ de julho do ano das eleições. Se houver coincidência de nomes, fica proibida a divulgação, sob pena de cancelamento do respectivo registro (Art. 45, VI).

O curioso é que, apesar de os candidatos comunicadores terem seus nomes afastados da programação midiática durante as eleições, muitos deles adotam em suas alcunhas de campanha o nome do canal em que trabalham. Por exemplo, o deputado estadual João Vitor Xavier Faustino, reeleito em 2014, tornou-se "João Vitor Xavier da Itatiaia". O deputado estadual Douglas Melo Soares Estanislau registrou sua candidatura denominando-se "Douglas Melo da Musirama". E Mário Henrique "Caixa" adotou em seu nome o bordão pelo qual se tornou famoso na Rádio Itatiaia ao narrar os gols do Clube Atlético Mineiro. Ele foi o segundo deputado mais bem votado em Minas Gerais, com 130.593 votos.

A propaganda política é um dos mais eficientes meios de candidatos e partidos atingirem os eleitores e veicularem suas plataformas e projetos políticos. Por isso, é alvo de rigorosa atenção pela Lei Eleitoral, que dispõe sobre o assunto nos arts. 36 e seguintes. Vale ressaltar que, no interior do gênero propaganda política, existem pelo menos três diferentes espécies, conforme explica o eleitoralista Joel J. Cândido (2008, p. 151-152): propaganda eleitoral (usada para captação de eleitores e somente permitida após o dia 5 de julho do ano da eleição, de acordo com o Art. 36, caput); propaganda intrapartidária (usada no interior do partido antes da escolha do candidato); e propaganda política partidária (veiculada em época de eleição ou fora dela para divulgar programa ou proposta política do partido).

Quando a Lei discrimina diferentes espécies de propaganda política e determina as diretrizes a serem seguidas por partidos e candidatos na exploração desse instrumento de comunicação, ela trata, sobretudo, de formatos midiáticos com propósito específico e revelado de atingir e influenciar o público eleitor. O problema é que, frequentemente, a propaganda eleitoral é capaz de atingir os eleitores de forma camuflada e oculta (RIBEIRO, 2000). Uma vez que o 
parlamentar ou candidato tem lugar cativo na mídia e possui credibilidade com os ouvintes, aproveitar tal espaço para dissimular um discurso político é uma estratégia conveniente.

Para exemplificar essa situação, reproduzir-se-á trecho do programa "O Povo no Rádio", sucesso de audiência da Rádio Musirama, de Sete Lagoas, em que o deputado Douglas Melo tem participação diária sendo, inclusive, tratado como parlamentar a todo o tempo. Ele relata um encontro com o governador de Minas Gerais, Fernando Pimentel:

Eu conversei com o Pimentel semana passada [...] e passei algumas situações para ele, dois pedidos em especial: a questão da segurança, que a gente já está vendo como a sensação de segurança de Sete Lagoas mudou [...], conversei sobre isso com o Pimentel, e ele falou que este ano vão chegar viaturas novas para a PM. E fiz um pedido, também em especial, que é a duplicação de Sete Lagoas a Pedro Leopoldo. [...] O governador anotou na própria agenda. Eu falei: 'governador, se o senhor fizer isso, a região inteira vai abraçá-lo em qualquer eleição que o senhor estiver, porque ninguém nunca duplicou essa estrada'. [...] Tomara que o nosso governador atenda. A nossa expectativa é que no ano que vem essas obras possam se iniciar. Não é promessa, porque eu não prometo, mas o governador disse que vai se empenhar. ${ }^{11}$

Torna-se evidente, portanto, que o deputado utiliza o espaço de grande audiência que possui no rádio para dar publicidade a seus feitos como agente público, o que, no mínimo, tende a induzir a aprovação do eleitorado. Noticiar o encontro com o governador o estado confere ao parlamentar atributos de eficiência e força política, temperados pela expectativa da realização de uma grande obra pública para população de Sete Lagoas.

O discurso adotado por Douglas Melo tem forte caráter personalista, distanciando-se do ideal de neutralidade exigido na atividade administrativa. Sem a menor desfaçatez, ele se coloca aos ouvintes como deputado - e não como locutor - e noticia, na primeira pessoa, suas ações em prol do município. Na visão de Cármen Lúcia Rocha (1994), a autopromoção pelo cargo público propicia benefícios e privilégios ao político, inclusive, no sentido de que ele permaneça nos órgãos poder.

Ainda que aquela promoção se dê com recursos particulares, mas orientando-se para a projeção pública de determinado agente, haverá violação do princípio da impessoalidade, pois sua situação caracterizará o comportamento, o seu nome, símbolo, etc., tornando pessoal uma atividade que tem que ser neutra e impessoal. (ROCHA, 1994, p. 169).

\footnotetext{
${ }^{11}$ Melo (2015).
} 
Atenta-se para o fato de que a Lei 9.504/97 não considera propaganda antecipada "a participação de filiados a partidos políticos ou de pré-candidatos em entrevistas, programas, encontros ou debates no rádio, na televisão e na internet, inclusive com a exposição de plataformas e projetos políticos" (Art. 36-A, I). Porém, a legislação acrescenta na segunda parte do mesmo artigo que deve ser "observado pelas emissoras de rádio e de televisão o dever de conferir tratamento isonômico". Diferentemente disso, o que se depreende de exemplos como o citado acima é o uso permanente e exclusivo do espaço midiático para a promoção de projetos e conquistas do referido parlamentar, sem que haja oportunidade semelhante a outros políticos.

Outra inquietação surge quando esses administradores aproveitam o prestígio midiático para divulgar suas páginas oficiais na internet. Frequentemente dotados de muito carisma com os ouvintes, os radialistas são, algumas vezes, figuras bastante ativas nas redes sociais. Quando estão no ar por suas respectivas emissoras, em diversas ocasiões, mencionam seus perfis digitais, espaço em que o diálogo travado com público é ainda mais próximo. Entretanto, ao acessar a página do comunicador, o ouvinte se deparará também com o político, seus projetos e suas ações na comunidade. Em resumo, configura-se também uma maneira indireta de empregar a mídia, de forma não igualitária, na promoção do parlamentar.

\section{Os deputados radialistas e a frequência na ALMG}

Como demonstrado, a legislação brasileira não obsta a um comunicador manter suas atividades nos veículos de radiodifusão quando investido em um cargo público eletivo. Entretanto, o exercício concomitante de duas funções pode acarretar um eventual conflito entre compromissos agendados para uma mesma data. Em face disso, procurou-se observar a frequência dos deputados radialistas da ALMG em reuniões ordinárias no Plenário e em suas respectivas Comissões, durante o período de $1^{\circ}$ de fevereiro a 30 de junho de 2015.

As reuniões ordinárias da Assembleia Legislativa realizam-se no Plenário, às terças, quartas e quintas-feiras úteis, a partir das 14h, e requerem número regimental mínimo de 1/3 dos membros da Casa. Esses encontros se destinam à discussão e votação de projetos de Lei, articulações, negociações políticas e debates sobre temas de interesse da população. Dispõem a Constituição Estadual (Art. 58) e o Regimento Interno (Art. 53) que perderá o mandato o 
deputado que não comparecer, em cada sessão legislativa ${ }^{12}$, a 1/3 das reuniões ordinárias, salvo em caso de licença ou missão autorizada pela Assembleia.

A tolerância com ausências é mais rígida quando se trata de disciplinas relativas a parâmetros éticos desejáveis para a administração pública. A Resolução 5.207, de 10 de dezembro de 2002, contemplada pelo Regimento Interno, sinaliza nesse sentido:

Art. $2^{\circ}$ - Consideram-se incompatíveis com a ética e o decoro parlamentar: [...] c) a ausência, em cada sessão legislativa ordinária, à quinta parte das reuniões ordinárias de caráter deliberativo da Assembleia ou da comissão permanente de que o Deputado seja membro, salvo nos casos de licença ou de missão autorizada.

De antemão, salienta-se que o levantamento realizado nesta pesquisa não permitirá apontar qualquer afronta aos preceitos estabelecidos pelos textos normativos supracitados, já que o período analisado não compreende a integridade da sessão legislativa ordinária. Ainda assim, apresentar-se-ão os resultados parciais para que, posteriormente, possam ser esboçadas algumas ilações decorrentes desses dados. Os quadros seguintes mostram a frequência mensal dos deputados às reuniões ordinárias deliberativas realizadas no Plenário da ALMG ${ }^{13}$ :

Deputado João Vítor Xavier (PSDB)

\begin{tabular}{|c|c|c|c|}
\hline MÊS & $\mathrm{N}^{\circ}$ DE REUNIÕES ORDINÁRIAS & $\mathrm{N}^{\circ}$ DE PRESENÇAS & PERCENTUAL \\
\hline FEVEREIRO & 9 & 8 & $88,88 \%$ \\
\hline MARÇO & 12 & 9 & $75 \%$ \\
\hline ABRIL & 11 & 9 & $81,81 \%$ \\
\hline MAIO & 11 & 8 & $72,72 \%$ \\
\hline JUNHO & 10 & 7 & $70 \%$ \\
\hline TOTAL & 53 & 41 & $77,35 \%$ \\
\hline
\end{tabular}

Deputado Douglas Melo (PSC)

\begin{tabular}{|c|c|c|c|}
\hline MÊS & $\mathrm{N}^{\circ}$ DE REUNIÕES ORDINÁRIAS & $\mathrm{N}^{\circ}$ DE PRESENÇAS & PERCENTUAL \\
\hline FEVEREIRO & 9 & 9 & $100 \%$ \\
\hline MARÇO & 12 & 10 & $83,33 \%$ \\
\hline ABRIL & 11 & 10 & $90,9 \%$ \\
\hline MAIO & 11 & 10 & $90,9 \%$ \\
\hline JUNHO & 10 & 7 & $70 \%$ \\
\hline TOTAL & 53 & 46 & $86,79 \%$ \\
\hline
\end{tabular}

Deputado Mário Henrique Caixa (PC do B)

\begin{tabular}{|c|c|c|c|}
\hline MÊS & $\mathrm{N}^{\circ}$ DE REUNIÕES ORDINÁRIAS & $\mathrm{N}^{\circ}$ DE PRESENÇAS & PERCENTUAL \\
\hline FEVEREIRO & 9 & 8 & $88,88 \%$ \\
\hline
\end{tabular}

\footnotetext{
${ }^{12}$ A sessão legislativa ordinária corresponde ao calendário anual das atividades do Poder Legislativo. Ocorre de $1^{\circ}$ de fevereiro a 18 de julho e de $1^{\circ}$ de agosto a 20 de dezembro de cada ano.

${ }^{13} \mathrm{O}$ comparecimento dos deputados às reuniões ordinárias é registrado no Diário do Legislativo, que pode ser acessado na página oficial da ALMG.
} 


\begin{tabular}{|c|c|c|c|}
\hline MARÇO & 12 & 9 & $75 \%$ \\
\hline ABRIL (ATÉ 15/04) & 6 & 3 & $50 \%$ \\
\hline TOTAL & 27 & 20 & $74,07 \%$ \\
\hline
\end{tabular}

Os números mostram que o comparecimento dos deputados a reuniões ordinárias do Plenário é regular, e, se tomados os dados como tendência para o restante da sessão legislativa, nenhum deles terá infringido as normas regimentais que determinam perda de mandato àquele que deixar de comparecer a 1/3 dos encontros. Contudo, os resultados parciais apontam que apenas o deputado Douglas Melo tem atendido ao requisito da Resolução 5.207/02, que considera incompatível com a ética e o decoro parlamentar a ausência a 20\% das reuniões deliberativas.

Ao deixar de comparecer a uma reunião, o deputado pode escolher entre justificar ou não a sua falta naquela data. Num ou noutro caso, a ausência será computada. Porém, há situações em que o deputado pode requerer uma licença para se afastar de suas atividades no Legislativo, por meio de documento fundamentado dirigido à Presidência da Assembleia, nos termos do Art. 54 do Regimento Interno. ${ }^{15}$

Com base no inciso IV do referido dispositivo, que trata de licenças não remuneradas para fins de interesse particular, o deputado João Vítor Xavier ausentou-se da Assembleia entre os dias 19 e 21 de maio de 2015. No documento encaminhado ao Presidente da Casa - e postado em suas redes sociais -, o parlamentar citou como razão para o afastamento uma "viagem ao exterior". O destino, não especificado no requerimento, era Buenos Aires, para acompanhar a partida entre River Plate e Cruzeiro, no dia 21 de maio, pela Rádio Itatiaia.

O então deputado Mário Henrique Caixa, por sua vez, também esteve em viagem ao exterior para narrar a partida entre Atlas, do México, e Atlético Mineiro, pela Copa Libertadores da América. O duelo foi realizado no dia 15 de abril, na cidade de Guadalajara, mas o

\footnotetext{
${ }^{14}$ Data da nomeação do deputado como Secretário de Estado do Turismo.

15 “Art. 54 - Será dada licença ao Deputado para:

I - chefiar missão temporária de caráter diplomático;

II - participar de curso, congresso, conferência ou reunião considerados de interesse da atividade parlamentar;

III - tratar da saúde, quando, por motivo de doença comprovada, se encontrar impossibilitado de cumprir os deveres decorrentes do exercício do mandato;

IV - tratar, sem remuneração, de interesse particular, desde que o afastamento não ultrapasse 120 (cento e vinte) dias por sessão legislativa ordinária.

$\S 1^{\circ}$ - A licença depende de requerimento fundamentado, dirigido ao Presidente da Assembleia Legislativa. $\S 2^{\circ}$ - A licença será concedida pelo Presidente, de ofício ou a requerimento, exceto nas hipóteses dos incisos I e IV, em que a decisão caberá à Mesa da Assembleia [...]”. (MINAS GERAIS, 2002).
} 
parlamentar esteve distante de suas atividades na Assembleia pelo menos desde o dia 13 do mesmo mês. ${ }^{16}$

Além das reuniões em Plenário, os deputados devem comparecer às suas respectivas Comissões Temáticas, nas quais, entre outras atribuições, discutem e opinam sobre projetos em tramitação na ALMG. A frequência aos encontros desses grupos também é registrada. Se o parlamentar faltar a cinco reuniões ordinárias consecutivas ou 10 alternadas, na mesma sessão legislativa, haverá perda do lugar na Comissão em que for membro efetivo (Art. 116, §², do Regimento Interno).

Para esta análise, focalizaram-se as Comissões Permanentes nas quais os parlamentares são membros efetivos. O deputado Douglas Melo integra efetivamente duas Comissões Educação, Ciência e Tecnologia, da qual é vice-presidente, e Defesa do Consumidor e do Contribuinte, além de figurar como suplente em outras duas. O deputado João Vítor Xavier aparece como efetivo na Comissão de Esporte, Lazer e Juventude e na Comissão de Minas e Energia. Como suplente, seu nome está registrado em outras quatro. Por sua vez, enquanto deputado estadual, Mário Henrique Caixa foi membro efetivo e vice-presidente da Comissão de Esporte, Lazer e Juventude, e suplente em outras duas.

Abaixo, apresenta-se a relação de comparecimento dos deputados, mês a mês, até o dia 30 de junho, às reuniões ordinárias das respectivas Comissões.

Deputado João Vítor Xavier (PSDB)

\begin{tabular}{|c|c|c|c|}
\hline COMISSÃO & MÊS & N $^{\circ}$ DE REUNIÕES ORDINÁRIAS & $N^{\circ}$ DE PRESENÇAS \\
\hline \multirow{4}{*}{ Minas e Energia } & Fevereiro & 0 & - \\
\cline { 2 - 4 } & Março & 3 & 0 \\
\cline { 2 - 4 } & Abril & 5 & 0 \\
\cline { 2 - 4 } & Maio & 3 & 0 \\
\cline { 2 - 4 } & Junho & 3 & 0 \\
\hline \multirow{4}{*}{ Esporte, Lazer e Juventude } & Fevereiro & 3 & 1 \\
\cline { 2 - 4 } & Março & 1 & 0 \\
\cline { 2 - 4 } & Abril & 3 & 1 \\
\cline { 2 - 4 } & Maio & 4 & 0 \\
\cline { 2 - 4 } & Junho & 3 & 0 \\
\hline
\end{tabular}

\section{Deputado Douglas Melo (PSC)}

\footnotetext{
${ }^{16}$ No dia 13 de abril de 2015 foi realizada a $3^{\mathrm{a}}$ Reunião Especial no Plenário da ALMG, destinada a homenagear o Partido Comunista do Brasil (PC do B), legenda do então deputado Mário Henrique. Em seu discurso, o deputado Celinho do Sinttrocel justificou a ausência do correligionário, referindo-se à viagem ao México. Suas palavras estão transcritas no Diário do Legislativo do dia 17 de abril de 2015.
} 


\begin{tabular}{|c|c|c|c|}
\hline COMISSÃO & MÊS & N $^{\circ}$ DE REUNIÕES ORDINÁRIAS & $N^{\circ}$ DE PRESENÇAS \\
\hline \multirow{4}{*}{$\begin{array}{c}\text { Educação, Ciência e } \\
\text { Tecnologia }\end{array}$} & Fevereiro & 1 & 1 \\
\cline { 2 - 4 } & Março & 2 & 1 \\
\cline { 2 - 4 } & Abril & 2 & 3 \\
\cline { 2 - 4 } & Maio & 3 & 0 \\
\cline { 2 - 4 } & Junho & 2 & 3 \\
\cline { 2 - 4 } $\begin{array}{c}\text { Defesa do Consumidor e do } \\
\text { Contribuinte }\end{array}$ & Fevereiro & 3 & 4 \\
\cline { 2 - 4 } & Março & 4 & 4 \\
\cline { 2 - 4 } & Abril & 4 & 1 \\
\cline { 2 - 4 } & Maio & 2 & 3 \\
\hline
\end{tabular}

Deputado Mário Henrique Caixa (PC do B)

\begin{tabular}{|c|c|c|c|}
\hline COMISSÃO & MÊS & No DE REUNIÕES ORDINÁRIAS & $\mathrm{N}^{\circ}$ DE PRESENÇAS \\
\hline \multirow{3}{*}{ Esporte, Lazer e Juventude } & Fevereiro & 0 & - \\
\hline & Março & 3 & 3 \\
\hline & Abril (até 15/04) & 1 & 0 \\
\hline
\end{tabular}

O primeiro quadro revela que o deputado João Vítor Xavier não seguiu, nos primeiros meses de mandato, uma rotina de comparecimento regular às reuniões ordinárias nas Comissões em que é membro efetivo. Na Comissão de Minas Energia, por exemplo, ele faltou a todos os 14 encontros, sendo, na maioria das vezes, substituído por outros deputados. Se tomados como base os preceitos do Art. 116 do Regimento Interno, não haveria outra inferência, senão a possibilidade de haver perda de lugar. Mesmo na Comissão de Esporte, Lazer e Juventude, tema ao qual é familiarizado por sua atuação na imprensa, não houve assiduidade às reuniões ordinárias, tendo o parlamentar estado presente em apenas duas, das 11 realizadas.

Já o deputado Douglas Melo possui um histórico de frequência melhor nas Comissões de que faz parte. Na Comissão de Educação, Ciência e Tecnologia, ele compareceu a 60\% das reuniões até o mês de junho. E na Comissão de Defesa do Consumidor e do Contribuinte ausentou-se em apenas uma oportunidade. Além desses dados, a pesquisa demonstrou que, entre os parlamentares radialistas, Douglas Melo é aquele que mais está presente em encontros de outras Comissões, das quais não é efetivo nem suplente, como de Segurança Pública; Saúde; Transporte, Comunicação e Obras Públicas etc.

Por fim, ressalta-se a presença do então deputado Mário Henrique Caixa às reuniões da Comissão de Esporte, Lazer e Juventude. Ele compareceu aos três primeiros encontros e faltou a apenas um, antes de ser nomeado Secretário de Estado. Nota-se que a única ausência foi registrada justamente quando o parlamentar estava no México, para a cobertura de uma partida de futebol. 
À vista de todos esses números, conclui-se que, em algumas ocasiões, os políticos não compareceram às reuniões ordinárias por estarem desempenhando suas atividades no rádio, espaço em que raramente há flexibilidade de horários. A legislação não veda essa prática de forma expressa, mas resta claro que as funções podem ser conciliadas sem que o parlamentar precise se ausentar do Plenário. Com a tecnologia de radiodifusão disponível nos dias atuais, não é indispensável que o radialista esteja no local do evento para transmiti-lo. Cabe, por isso, problematizar a escolha dos deputados que priorizam as atividades da mídia em detrimento dos compromissos firmados como agentes públicos.

No próximo tópico, veremos que a Constituição Estadual, com respaldo na Constituição da República, veda aos deputados estaduais o exercício de determinados cargos, funções ou atividades. Analisemos, então, a possibilidade de vislumbrar, nesse rol, a atuação de políticos em veículos de radiodifusão.

\section{As incompatibilidades constitucionais e a função em empresas radiodifusoras: uma leitura possível?}

As incompatibilidades constitucionais são impedimentos dirigidos aos parlamentares com o propósito de coibir o exercício de funções, cargos, empregos ou atividades em determinadas instituições que tenham algum laço com o poder público. Elas mostram a preocupação do legislador com a preservação da dignidade, moralidade e autonomia do Poder Legislativo, de modo a evitar o uso da condição política para objetivos escusos e proveitos pessoais (CARVALHO, 2013).

O texto da Constituição do Estado de Minas Gerais, em seu Art. 57, submete os deputados estaduais às mesmas incompatibilidades previstas na Constituição Federal para deputados federais e senadores (Art. 54). Ressaltam-se, para os fins deste trabalho, aquelas elencadas pelo inciso I, alíneas "a" e "b":

Art. 57 - O Deputado não pode: I - desde a expedição do diploma:

a) firmar ou manter contrato com pessoa jurídica de direito público, autarquia, empresa pública, sociedade de economia mista ou empresa concessionária de serviço público, salvo quando o contrato obedecer a cláusulas uniformes;

b) aceitar ou exercer cargo, função ou emprego remunerado, incluídos os de que seja demissível ad nutum, nas entidades indicadas na alínea anterior; [...] 
Os serviços de radiodifusão sonora e de sons e imagens estão incorporados na Constituição Federal dentro das competências da União (Art. 21, XII, “a” e Art. 223), podendo ser explorados diretamente pelo Estado ou mediante outorga do direito de execução a empresas privadas, por meio de concessões, permissões ou autorizações. A despeito de muitas discussões doutrinárias, a corrente majoritária dos autores que enfrentaram o tema entende que a atividade radiodifusiva está contemplada no conceito de serviço público, mesmo esta não sendo também uma noção precisa. ${ }^{17}$

Isso posto, cumpre dizer que a União, possuidora exclusiva das frequências e canais de rádio e $\mathrm{TV}$, transfere a particulares o direito de uso, em regra, pelos instrumentos da concessão e da permissão. Conceitua o Decreto $\mathrm{n}^{\mathrm{o}}$ 52.795/63, que aprova o regulamento dos serviços de radiodifusão, a concessão como "a autorização outorgada pelo poder competente a entidades executoras de serviços de radiodifusão sonora de caráter nacional ou regional e de televisão”. Já a permissão "é a autorização outorgada pelo poder competente a entidades para a execução de serviço de radiodifusão de caráter local”.

Quanto à competência da outorga, caberá ao Presidente da República fazê-lo, por meio de concessão, quando tratar-se de exploração de canais de televisão. O serviço destinado à geração de sons (rádio), por sua vez, será outorgado pelo Ministro das Comunicações, mediante permissão, concessão ou autorização (redação dada pelo Art. $6^{\circ}, \S \S 1^{\circ}$ e $2^{\circ}$, do Decreto 7.670/2012). Os prazos serão de 10 anos para os serviços ligados à radiodifusão sonora e 15 anos para o de televisão (Art. 27 do Decreto no 52.795/63).

Conforme sistematiza Pinto (1992), se dá por concessão a outorga dos seguintes serviços de radiodifusão comercial: onda média $(\mathrm{OM})$ com mais de $1 \mathrm{KW}$ de potência, onda tropical (OT) onda curta (OC) e geração de sons e imagens (TV). A permissão, por seu turno, é meio de transferência das frequências moduladas (FM) e ondas médias (OM) de até $1 \mathrm{KW}$.

O que se pretende demonstrar, portanto, é que se a radiodifusão pode ser compreendida como um serviço público que se estende à sociedade de forma abrangente e essencial por meio de outorgas, os deputados que exercem cargo, função ou emprego remunerado em empresas concessionárias desse serviço estariam contrariando uma norma constitucional. E, por esse raciocínio, uma interpretação extensiva permitiria também a inclusão de entidades

\footnotetext{
${ }^{17}$ Para aprofundamento no assunto, ver Grau (2012), Lopes (1997) e Wimmer; Pieranti (2009).
} 
permissionárias nessa relação. Destaca-se que o descumprimento do referido item pode, inclusive, acarretar a perda do mandato, nos termos do Art. 55 da Constituição Federal e Art. 58 da Constituição Estadual.

Essa, no entanto, não é uma leitura inédita para o dispositivo. Com base no mesmo Art. 54 da Constituição Federal (correspondente ao Art. 57 da Constituição Estadual supratranscrito), tem sido discutida, a passos lentos, a possibilidade de proibir que parlamentares figurem como proprietários, controladores, diretores ou administradores de empresas de radiodifusão. O questionamento ganha relevo em meio a um universo numérico significativo de companhias que sofrem influência direta de políticos: dados das eleições de 2014, por exemplo, mostram que 32 emissoras de TV, 141 rádios e 16 jornais impressos pertenciam a candidatos que disputaram aquele pleito. ${ }^{18}$

A inquietação decorrente da matéria fez dela, em 2009, um dos objetos tratados pelo relatório da Subcomissão Especial de Radiodifusão - órgão criado pela Comissão de Ciência, Tecnologia, Comunicação e Informática da Câmara dos Deputados, para analisar mudanças nas normas de apreciação dos atos de outorga e renovação de concessão, permissão ou autorização de serviço de radiodifusão sonora e de sons e imagens. Os parlamentares responsáveis pelo documento recomendaram a discussão de uma Proposta de Emenda Constitucional para regulamentar a vedação à propriedade de veículos de rádio e TV por políticos. O principal argumento lançado na proposição atrela-se à divergência dos interesses envolvidos:

Como o Congresso Nacional é responsável pela apreciação dos atos de outorga e renovação de outorga de radiodifusão, a propriedade e a direção de emissoras de rádio e televisão são incompatíveis com a natureza do cargo político e o controle sobre concessões públicas, haja vista o notório conflito de interesses. (BRASIL, 2009, p. 5354).

Dois anos depois, abordagem semelhante chegou ao STF por meio da Arguição por Descumprimento de Preceito Fundamental (ADPF) 246, elaborada pelo coletivo Intervozes em parceria com o Partido Socialismo e Liberdade (PSOL). O principal objetivo é demonstrar a inconstitucionalidade da concessão de outorgas de radiodifusão a emissoras controladas por titulares de cargos públicos eletivos. Além de reforçarem a violação ao Art. 54 da Constituição Federal, os autores defendem que a prática contraria o direito à informação (Art. $5^{\circ}$ ), o direito à

\footnotetext{
${ }^{18}$ Ver Alessi (2014).
} 
realização de eleições livres (Art. 60), o princípio da isonomia, a isenção e a independência dos membros do Legislativo, entre outros preceitos fundamentais.

No plano internacional, há países que estabelecem restrições ao exercício de cargos e funções paralelas às atividades no Parlamento. Nos Estados Unidos, algumas diretrizes estão instituídas nas Rules of the House of Representatives, dentre as quais figura a vedação ao recebimento de qualquer remuneração fora do Congresso que ultrapasse $15 \%$ dos subsídios anuais da categoria de nível 2 do Executivo. ${ }^{19} \mathrm{Na}$ África do Sul, as especificações são ainda mais rígidas. O Código de Conduta do Parlamento proíbe expressamente que os congressistas tenham outro emprego remunerado fora do Legislativo, salvo quando a atividade for compatível com a função do representante público e tiver a sanção do partido ao qual ele pertence. ${ }^{20}$ Por fim, na seção de proibições do Código de Condutas Parlamentares do Chile, há referências similares àquelas dispostas na Constituição brasileira sobre o exercício de funções em empresas concessionárias de serviços públicos. Dispõe o Art. 8, alínea "d” que os deputados chilenos não podem "dirigir, patrocinar ou prestar serviços, remunerados ou não, a pessoas naturais ou

${ }^{19}$ As limitações à renda obtida fora do Parlamento estão especificadas na Rule XXV:

LIMITATIONS ON OUTSIDE EARNED INCOME AND ACCEPTANCE OF GIFTS

"Outside earned income; honoraria

1. (a) Except as provided by paragraph (b), a Member, Delegate, Resident Commissioner, officer, or employee of the House may not - (1) have outside earned income attributable to a calendar year that exceeds 15 percent of the annual rate of basic pay for level II of the Executive Schedule under section 5313 of title 5, United States Code, as of January 1 of that calendar year; or (2) receive any honorarium, except that an officer or employee of the House who is paid at a rate less than 120 percent of the minimum rate of basic pay for GS-15 of the General Schedule may receive an honorarium unless the subject matter is directly related to the official duties of the individual, the payment is made be-cause of the status of the individual with the House, or the person offering the honorarium has interests that may be substantially affected by the performance or nonperformance of the official duties of the individual." Disponível em: <http://clerk.house.gov/legislative/house-rules.pdf>. Acesso em: 21 jun. 2015.

${ }^{20}$ O Código de Conduta do Parlamento sul-africano estatui sobre a remuneração proveniente de outro emprego com as seguintes determinações:

“7. REMUNERATED EMPLOYMENT OUTSIDE OF PARLIAMENT

7.1 No Member shall perform or undertake remunerated employment or work outside of Parliament, which does not strictly fall within the employment or work sanctioned in terms of clause 7.2 and which has been recorded in the ATC in terms of clause 7.3;

7.2 A Member may only perform or undertake remunerated employment or work outside of Parliament when such employment or work is sanctioned by the political party to which the Member belongs and is compatible with that Member's function as a public representative; and

7.3 In the event of a party agreeing to such employment of a Member outside of Parliament in terms of clause 7.2, the party must within 30 days provide the Registrar, in writing, with all the relevant details in this regard. If the Registrar is not satisfied that all the relevant information has been provided he or she must indicate to what extent the information must be supplemented and the party must within 30 days. When the Registrar is satisfied that all relevant information has been adequately provided by the relevant party, the Registrar must within 7 days cause such decision to be recorded in the ATC".

Disponível em: <http://www.parliament.gov.za/live/content.php?Category_ID=83>. Acesso em: 22 jun. 2015. 
jurídicas que giram ou explorem concessões ou privilégios da Administração do Estado, ou que forem seus provedores ou contratantes." 21

Em suma, os exemplos pontuais mostram que existe a preocupação de alguns países com a priorização da função pública por aqueles que alcançaram um cargo eletivo. Impor limites à remuneração extraparlamentar e às atividades fora do Congresso é, grosso modo, uma tentativa de moralizar e tornar mais eficiente a ação política, impedindo a aproximação de interesses divergentes que possam macular a missão de representar o interesse coletivo.

A relação entre políticos e veículos de comunicação, seja no controle dos bastidores, seja em contato com o público, torna possíveis circunstâncias que desafiam o próprio espírito da democracia, além de distorcerem o ideal jornalístico da informação verossímil e imparcial. A questão se complexifica na medida em que o debate em torno da mídia, no Brasil, tem raízes históricas e se segmenta em várias frentes, cujas definições, entretanto, longe da sociedade civil, figuram nas mãos de agentes interessados na manutenção de um sistema que permita perpetuá-los nas esferas de poder.

\section{Considerações finais}

Recentemente, o governo francês abriu uma série de discussões em torno dos conflitos de interesse que envolvem a vida dos políticos, procedimento que resultou na Lei Referente à Transparência da Vida Pública. ${ }^{22}$ Durante os debates, chegou a se cogitar impedir jornalistas ou comunicadores de exercerem um cargo público concomitantemente com sua profissão, proposta que acabou não se consolidando na Lei. De fato, essa generalização é perigosa: negar aos homens públicos o espaço que construíram na imprensa seria tolhê-los da liberdade de comunicação e informação, prerrogativas assentadas no rol dos direitos fundamentais e corolários da democracia. Por outro lado, isso não significa que essa relação entre

\footnotetext{
${ }^{21}$ Código de Conductas Parlamentarias de la Camara de Diputados de Chile. Disponível em <http://www.camara.cl/camara/media/docs/codigo_conducta.pdf $>$. Acesso em 22 jun. 2015.

${ }^{22}$ Disponível em: <www.legifrance.gouv.fr/affichTexte.do?cidTexte=JORFTEXT000028056315>. Acesso em: 13 ago. 2015.
} 
mídia e poder esteja aberta a permissividades, ficando isenta de qualquer forma de controle. ${ }^{23} \mathrm{~A}$ pergunta que permanece é a seguinte: haveria uma maneira de conciliar esse conflito?

Um estudo comparativo que perpassa esse tema, encomendado pelo Parlamento chileno, mostrou que os códigos de ética parlamentar, em diferentes países, estabelecem ao menos três pontos em comum: i) princípios gerais de conduta (como integridade, honradez, probidade, dignidade etc.); ii) a obrigação de declaração de interesses (casos em que possa haver um conflito entre as atividades ou atuação privada e pública do parlamentar); e iii) órgãos de controle (que podem envolver comissões internas, participação dos cidadãos e outras esferas de poder) (CHILE, 2002). ${ }^{24}$ Não há dúvidas de que esse arcabouço jurídico e institucional, que até certo ponto também está presente na realidade brasileira, traz as ferramentas necessárias para analisar o caso concreto, impedindo generalizações que possam cercear direitos e garantias fundamentais. $\mathrm{O}$ grande problema encontra-se na dificuldade de operacionalizar esses instrumentos, que muitas vezes esbarram em barreiras corporativistas e falta de motivação política para encarar os desafios.

Exemplo disso ocorreu com o então deputado federal Romário, em fevereiro de 2014, quando ele apareceu na televisão como estrela do comercial de uma marca de cerveja. Numa reportagem para a Folha de S.Paulo, a área técnica da Câmara afirmou que, "a princípio, não há impedimento legal em um deputado virar garoto-propaganda de uma empresa particular, embora a Comissão de Constituição e Justiça da Casa, que nunca analisou caso similar, possa ter posição diversa". ${ }^{25}$ Ou seja, na sequência, como ninguém se utilizou dos mecanismos institucionais para contestar o fato, as comissões da Câmara não puderam se manifestar a respeito do ocorrido.

Este artigo também mostrou diversos casos, envolvendo deputados comunicadores, em que a conduta do homem público poderia ser no mínimo questionada perante as Comissões ou o Conselho de Ética parlamentar. Chega-se ao ponto, neste estudo de caso envolvendo a Rádio Itatiaia, de os políticos fazerem anúncios para a Prefeitura de Belo Horizonte, que é patrocinadora da emissora. Assim, dependendo da conjuntura política, o parlamentar (ou seu partido) pode exercer o papel de oposição e criticar a administração durante o dia, para mais tarde, durante seu programa, anunciar que "BH é a melhor capital do Brasil", conforme o slogan da propaganda.

\footnotetext{
${ }^{23}$ A dificuldade reside na generalização. Por exemplo, há uma diferença entre um parlamentar que escreve um artigo para um jornal, uma vez por semana, e outro que tem um programa diário na rádio, como foi salientado nesta pesquisa.

${ }^{24} \mathrm{O}$ estudo envolveu os seguintes países: Grã-Bretanha, Estados Unidos, Portugal, Equador e El Salvador.

${ }^{25}$ Bragon e Falcão (2014).
} 
Diante desse quadro, o modelo de legislação americana parece interessante. Conforme vimos, ele não proíbe expressamente o acúmulo de funções, tal como ocorre na África do Sul, mas impõe uma série de restrições. Um quadro normativo mais consistente poderia servir para coibir abusos, como o caso das propagandas, e abrir espaço para uma análise mais detalhada dos casos concretos.

Mas muito além da omissão dos Conselhos de Ética parlamentar, este artigo trouxe um olhar sobre a ordem constitucional brasileira, buscando ferramentas para questionar essas condutas que trazem manifestos conflitos de interesse e constantes amálgamas entre valores de ordem pública e privada. Nesse sentido, vimos que, se o legislador não é capaz de propor leis objetivas que coíbam essas práticas ou se os mecanismos de controle interno dos Parlamentos são omissos, cabe ao Poder Judiciário, numa perspectiva de "filtragem Constitucional", fazer uma leitura axiológica do caso concreto, valendo-se em especial dos direitos e garantias fundamentais.

Para que isso seja concretizado, há diversos mecanismos processuais, envolvendo inclusive a participação dos cidadãos, além de ferramentas hermenêuticas e precedentes judiciais, conforme vimos ao longo deste artigo. Trata-se de uma tarefa difícil, capaz de trazer um conflito de Poderes, mas que não pode ser deixada de lado. Afinal, corrigir as distorções éticas nas instituições públicas e vencer a crise de descrédito enfrentada pela classe política são alguns dos grandes desafios da contemporaneidade.

\section{Referências}

ÁFRICA DO SUL. Parliament of the Republic of South Africa. Code of Ethical Conduct and Disclosure of Members' Interest for Assembly and Permanent Council Members. Cape Town, s/d. Disponível em: < http://www.parliament.gov.za/live/content.php?Category_ID=83>. Acesso em: 22 jun. 2015.

ALESSI, GIL. Candidatos têm 32 emissoras de TV e 141 rádios; prática não é regulamentada. UOL, São Paulo, não paginado, 01 ago. 2014. Disponível em: <http://eleicoes.uol.com.br/ 2014/noticias/2014/08/01/candidatos-tem-32-emissoras-de-tv-e-141-radios-pratica-nao-eregulamentada.htm>. Acesso em: 10 nov. 2015.

ALEXY, Robert. Teoria de los derechos fundamentales. Madrid: Centro de Estudios Constitucionales, 1997.

BARROSO, Luís Roberto. O direito constitucional e a efetividade de suas normas. Rio de janeiro: Renovar, 2004. 
BOURDIEU, Pierre. O poder simbólico. Rio de Janeiro: Bertrand Brasil, 2012.

BRAGON, Ranier; FALCÃO, Márcio. Em atitude rara, deputado vira garoto-propaganda de cerveja. Folha de S.Paulo, São Paulo, não paginado, 06 fev. 2014. Disponível em: <http:// www1.folha.uol.com.br/poder/2014/02/1408330-em-atitude-rara-deputado-vira-garotopropaganda-de-cerveja.shtml>. Acesso em: 05 out. 2015.

BRANDÃO, Antônio José. Moralidade Administrativa. Revista de Direito Administrativo, São Paulo, v. 25, p. 454-467, jul./set., 1951.

BRASIL. Decreto n ${ }^{\circ} 52.795$, de 31 de outubro de 1963. Aprova o Regulamento dos Serviços de Radiodifusão. Diário Oficial da União, Brasília, 1 nov. 1963.

BRASIL. Constituição (1988). Constituição da República Federativa do Brasil. Brasília: Senado Federal, 1988.

BRASIL. Lei 9.504, de 30 de setembro de 1997. Estabelece normas para as eleições. Diário Oficial da União, Brasília, 1 out. 1997.

BRASIL. Lei 9.784, de 29 de janeiro de 1999. Regula o processo administrativo no âmbito da Administração Pública Federa. Diário Oficial da União, Brasília, 30 jan. 1999.

BRASIL. Decreto n 7.670 , de 16 de janeiro de 2002. Altera dispositivos do Regulamento de Serviços de Radiodifusão aprovado pelo Decreto $n^{\circ} 52.795$, de 31 de outubro de 1963 , e dos Decretos $n^{\circ} 88.066$, de 26 de janeiro de 1983, e $n^{\circ} 5.820$, de 29 de junho de 2006. Diário Oficial da União, Brasília, 17 jan. 2002.

BRASIL. Supremo Tribunal Federal. Ação Declaratória de Constitucionalidade 12. Rel. Ministro Carlos Ayres Britto. Brasília: Diário de Justiça, 20 ago. 2008.

BRASIL. Congresso Nacional. Câmara dos Deputados. Comissão de Ciência e Tecnologia, Comunicação e Informática. Subcomissão Especial de Radiodifusão: Revisão de Normas de Concessão, Permissão e Autorização. Brasília: Câmara dos Deputados, Edições Câmara, 2009. Disponível em: <http://www2.camara.leg.br/atividade-legislativa/comissoes/comissoespermanentes/cctci/documentos/publicacoes.html/Rel-Radiodifusao.pdf $>$. Acesso em: 16 jun. 2015.

CÂNDIDO, Joel. Direito eleitoral brasileiro. 13. ed. Bauru, SP: Edipro, 2008.

CARVALHO, Kildare Gonçalves. Direito Constitucional positivo. v. 2. Belo Horizonte: Del Rey, 2013.

CHILE. Código de Conductas Parlamentarias. Santiago: Camara di Diputados, 2004. Disponível em: <https://www.camara.cl/camara/media/docs/codigo_conducta.pdf >. Acesso em: 22 jun. 2015. 
CHILE. Códigos de ética parlamentaria en la experiencia extranjera aspectos no considerados en el código de ética de la cámara de diputados de Chile. Valparaíso: Biblioteca del Congreso Nacional de Chile, 2002.

COSTA, Osmani Ferreira. Uma história política do rádio: a aventura eleitoral de radialistas no século XX em Londrina (PR). In: CONGRESSO NACIONAL DE HISTÓRIA DA MÍDIA, 5., São Paulo, 2007. Anais eletrônicos... São Paulo: Intercom, 2007. Disponível em: <http://www. intercom.org.br/papers/outros/hmidia2007/resumos/R0176-1.pdf>. Acesso em: 05 jan. 2015.

DI PIETRO, Maria Sylvia Zanella. Direito Administrativo. São Paulo: Atlas, 2012.

DWORKIN, Ronald. Taking rights seriously. Cambridge: Harvard University Press, 1997.

ESTADOS UNIDOS DA AMÉRICA. United States House of Representatives. Rules of the House of Representatives. Washington: Clerk of the House of Representatives, 2015. Disponível em: < http://clerk.house.gov/legislative/house-rules.pdf >. Acesso em: 21 jun. 2015.

FRANÇA. Assemblée Nationale. Fiche de synthèse no 16: Le statut du deputé. Paris: Bureau de l'Assemblée Nationale, 2014. Disponível em: < http://www2.assemblee-nationale.fr/decouvrir-1assemblee/role-et-pouvoirs-de-l-assemblee-nationale/le-depute/le-statut-du-depute>. Acesso em: 21 jun. 2015.

FRANÇA. Loi no 2013-907, du 11 octobre 2013. Relative à la transparence de la vie republique. Paris, 11 out. 2013. Disponível em: <https://www.legifrance.gouv.fr/affichTexte.do?cidTexte= JORFTEXT000028056315>. Acesso em: 13 ago. 2015.

GRAU, Eros Roberto. A ordem econômica na Constituição de 1988: interpretação e crítica. São Paulo: Malheiros, 2012.

HESSE, Konrad. A força normativa da Constituição. Porto Alegre: Sergio Fabris Editor, 1991.

LOPES, Vera Maria de Oliveira Nusdeo. O direito à informação e as concessões de rádio e televisão. São Paulo: Editora Revista dos Tribunais, 1997.

MELO, Douglas: depoimento [jul. 2015]. Entrevistador: Geraldo Padrão. Sete Lagoas, MG: Rádio Musirama FM, 2015. Duração 1h05.

MENDES, Gilmar Ferreira. Os direitos fundamentais e seus múltiplos significados na ordem constitucional. Revista Eletrônica de Direito do Estado, Salvador, n. 23, p. 1-12, jul./set. 2010. Disponível em: <http://www.direitodoestado.com/revista/REDE-23-JULHO-2010-GILMARMENDES.pdf>. Acesso em: 13 fev. 2015.

MINAS GERAIS. Constituição (1989). Constituição do Estado de Minas Gerais. 15. ed. Belo Horizonte: Assembleia Legislativa de Minas Gerais, 2013.

MINAS GERAIS. Assembleia Legislativa. Regimento Interno da Assembleia Legislativa.10. ed. Belo Horizonte: Assembleia Legislativa do Estado de Minas Gerais, 2015. 
MOREIRA NETO, Diogo de Figueiredo. Moralidade administrativa: do conceito à efetivação. Revista de Direito Administrativo, Rio de Janeiro, v. 190, p. 1-44, out./dez. 1992.

NUNES, Márcia Vidal. Rádio e política: do microfone ao palanque: os radialistas políticos em Fortaleza (1982-1996). São Paulo: Annablume, 2000.

PINTO, Luciana Moraes Raso Sardinha. A radiodifusão no direito brasileiro. Belo Horizonte: Del Rey, 1992.

PORTO, Odyr; PORTO, Roberto. Apontamentos à Lei Eleitoral 9.504/97. São Paulo: Malheiros Editores, 1998.

PORTUGAL. Assembleia da República de Portugal. Estatuto dos Deputados: Lei no 7/93, de 1 de março, com as alterações introduzidas pela Lei $n^{\circ}$ 24/95, de 18 de agosto, Lei $n^{\circ} 55 / 98$, de 18 de agosto, Lei no 8/99, de 10 de fevereiro, Lei no 45/99, de 16 de junho, Lei $n^{\circ}$ 3/2001, de 23 de fevereiro (rectificada pela Declaração de Rectificação n. ${ }^{\circ}$ 9/2001, de 13 de Março), Lei n. ${ }^{\circ}$ 24/2003, de 4 de Julho, Lei n. ${ }^{\circ}$ 52-A/2005, de 10 de outubro, Lei n. ${ }^{\circ}$ 44/2006, de 25 de agosto, Lei n. ${ }^{\circ}$ 45/2006, de 25 de agosto, Lei n. ${ }^{\circ} 43 / 2007$, de 24 de agosto e Lei n. ${ }^{\circ}$ 16/2009, de 1 de Abril. Diário Oficial da República, Lisboa, s/d. Disponível em: <http://www.parlamento.pt/ Legislacao/Documents/Legislacao_Anotada/EstatutoDeputados_Simples.pdf >. Acesso em: 21 jun. 2015.

RIBEIRO, Fávila. Direito Eleitoral. Rio de Janeiro: Editora Forense, 2000.

ROCHA, Cármen Lúcia Antunes. Princípios Constitucionais da Administração Pública. Belo Horizonte: Del Rey, 1994.

RUBIM, Antonio Albino Canelas; AZEVEDO, Fernando Antonio. Mídia e política no Brasil: textos e agenda de pesquisa. Lua Nova, São Paulo, n. 43, p. 189-216, 1998. Disponível em: $<$ http://www.scielo.br/scielo.php?script=sci_arttext\&pid=S0102-64451998000100011\&lng= en\&nrm=iso>. Acesso em: 12 jan. 2016.

SILVA, Maurício. “Quem me elegeu foi o rádio": como o rádio elege seu representante. São Paulo: Olho d'Água, 2000.

TÁCITO, Caio. Moralidade administrativa. Revista de Direito Administrativo, Rio de Janeiro, v. 218, p. 1-10, out./dez. 1999.

WEBER, Max. Le savant et le politique. Paris: La Découverte, 2003.

WIMMER, Miriam; PIERANTI, Octavio Penna. Serviços públicos de radiodifusão? Incoerências, insuficiências e contradições na regulamentação infraconstitucional. Revista Eletrônica Internacional de Economia Política da Informação da Comunicação e da Cultura, Sergipe, v. 11, n. 1, não paginado, jan./abr. 2009. Disponível em: <http://www. seer.ufs.br/index.php/eptic/article/view/156>. Acesso em: 15 jul. 2015. 